\title{
Overview of Abnormal Uterine Bleeding in Adolescents: Diagnosis and Management
}

\author{
Yüce Özge ${ }^{1}$, Yüce Tuncay ${ }^{2}$, Çamurdan Mahmut Orhun ${ }^{1}$
}

\begin{abstract}
Abnormal uterine bleeding (AUB) is a frequent cause of visits to health care provider during adolescent period and is characterized by irregular, excessively heavy, prolonged and/or frequent bleeding of uterine origin. Although many etiologies cause AUB, the one most likely cause among adolescents are dysfunctional uterine bleeding (DUB). DUB describes any kind of abnormal bleeding pattern that is not attributable to any structural or systemic disease. Anovulation due to immaturity of the hypothalamic-pituitary-ovarian (HPO) axis is the leading cause in the first 2-3 postmenarchal years. The primary goal of treatment is prevention of hemodynamic instability. Therefore, assessing the severity and cause of bleeding is important. Therapeutic approach in the acute period should be established according to the degree of anemia and amount of flow. Treatment options for medical care of DUB generally include: oral contraceptives, progestins, non-steroidal anti inflammatory drugs, anti-fibrinolytic agents, $\mathrm{GnRH}$ analogues and levonorgestrel releasing intrauterine system (LNG-IUS). Additionally, long-term management with hormonal therapy in patients with severe uterine bleeding is known to be safe for developing HPO axis.

Keywords: Adolescent, Dysfunctional Uterine Bleeding, Therapeutics
\end{abstract}

\section{Introduction}

The Normal Menstrual Cycle and Abnormal Bleeding Menarche, which is a major landmark of female puberty, usually occurs within 2 to 3 years of the first appearance of breast budding or pubic hair (1). However, this period can feature individual and racial variances related to genetic and socio-economic factors. Many adolescents experience irregular cycles for the first 2 to 3 years after menarche due to immaturity of the hypothalamic-pituitary-ovarian (HPO) axis $(2,3)$. Hence, approximately half of menstrual cycles are anovulatory or have attenuated ovulation that results in luteal insufficiency (2).

Anovulatory cycles, which can result in normal menstrual bleeding, abnormal uterine bleeding (AUB) or amenorrhoea, gradually become characteristic ovulatory cycles. This process is related to the amount of time that has elapsed since menarche and the age at which menarche occurred. Early-onset menarche causes the early onset of ovulatory cycles (within 2-3 years). However, the gynaecological maturation process can be prolonged up to 6 years in some adolescent girls, particularly in those who have experienced menarche at a late age (4).

A normal menstrual cycle for adolescents is characterized by intervals of 21-40 days between menstrual bleeding and a period of menstrual bleeding lasting 2-7 days, with an expected blood loss of around 20-80 mL (5-10).

Abnormal bleeding can be identified as follows (6):

1. Menorrhagia: bleeding at intervals that are regular but lasting more than 7 days or a blood-loss volume of more than $80 \mathrm{~mL}$

2. Metrorrhagia: bleeding at irregular intervals

3. Menometrorrhagia: excessive bleeding $(>80 \mathrm{~mL})$ with frequent intervals

4. Oligomenorrhoea: bleeding with menstrual cycle intervals longer than 40 days

\section{Abnormal Uterine Bleeding}

AUB, defined as excessively heavy, prolonged and/or frequent bleeding of uterine origin or bleeding that occurs outside of normal cyclic menstruation, is one of the most common gynaecologic complaints of adolescents, as well as a cause of frequent visits to health care providers during its course $(6,7)$.

Although common, the incidence of AUB in adolescents has not been well documented because menstrual abnormalities (e.g. anovulation) in adolescents are more appropriately considered "symptomatic" rather than "physiologic" (2).

In one population-based study in Sweden, more than 1000 female students were surveyed about menstruation. Thirty-seven per cent of the participants, average age of 16.7 years, reported heavy menstrual bleeding ( $\mathrm{HMB})$, for which $12.5 \%$ of which required medical intervention (8). Similar rates have been reported in Turkey and Malaysia $(9,10)$.

Although AUB has many different aetiologies, its underlying pathology is recognized in less than $10 \%$ of abnormal bleeding cases. Moreover, the most likely cause of 
adolescent AUB is dysfunctional uterine bleeding (DUB) (6).

DUB is a diagnosis of exclusion and not attributable to any underlying structural or systemic disease. Generally, it is considered an anovulatory type of AUB. According to the European Society of Human Reproduction and Embryology (ESHRE), DUB can be either ovulatory or anovulatory (11).

Pathophysiology of Dysfunctional Uterine Bleeding The underlying pathophysiologic mechanisms leading to DUB are not well established. The absence of a sufficient luteinizing hormone $(\mathrm{LH})$ response that corresponds to the mid-cycle increase of estrogen due to a general immaturation of the HPO axis is considered to be the cause of anovulatory DUB. Thus, ovulation does not occur, and the ovarian follicles undergo atresia (12).

The endometrium is exposed to continuous estrogen stimulation and becomes hyperplasic. Progesterone production is absent, as the corpus luteum does not develop. The endometrium lacks the stabilizing effect of progesterone and therefore is sloughed off $(13,14)$.

Furthermore, the imbalance of prostaglandins (PGs) seems to play a role in ovulatory DUB. During menstruation, there is a disproportional rise in endometrial PGE2 as a result of the disruption of the balance between vasoconstrictor and vasodilator PGs, which may cause excessive, prolonged uterine bleeding. The imbalance of PGs has also been demonstrated in women with ovulatory DUB $(15,16)$.

\section{Diagnosis}

History and Physical Examination

The careful consideration and examination of each patient is crucial in the diagnosis of DUB and in determining appropriate treatment options. It is difficult to discern from the history whether the cycles are ovulatory or anovulatory. However, almost all cases of DUB in adolescents are known to originate from anovulatory cycles $(12,17)$. A late first menarche especially increases the possibility of the cycles being anovulatory, as it indicates that gynaecological maturation will also be delayed $(6,18)$.

Questions about cycle characteristics, such as cycle length, duration between cycles, pain and premenstrual symptoms (e.g. abdominal swelling and breast tenderness), should be asked, and, to ensure a clear interpretation of symptoms, the patient should keep a menstrual diary. The amount of bleeding can be evaluated by asking the patient about the number of pads used daily and the duration of bleeding. In clinical practice, menorrhagia is indicated by the use of more than three pads per day or by more than 6 full regular-absorbency tampons per day for 3 or more days (19).

A diagnostic evaluation should be performed before any treatment is initiated $(6,20)$. Pathologies such as bleeding disorders, clotting abnormalities, pathology of the reproductive tract, genital injuries and drug use should be excluded in the differential diagnosis process (Table 1). Pregnancy and pregnancy-related situations, such as ectopic pregnancy, should be promptly evaluated and excluded due to their high rates of morbidity and mortality (21).

Bleeding disorders, which cause $20 \%-33 \%$ of cases of prolonged and/or severe bleeding, should always be taken into consideration $(6,20)$. Continuous bleeding (as leakage) of long durations and occurring beginning with the first menstrual cycle should serve as a warning sign of coagulation disorders $(6,22)$. Additionally, patients should be queried as to whether they have a history of recurrent nasal bleeding, easy bruising, symptomatic anaemia or prolonged bleeding after surgery or tooth extraction (22).

Pelvic inflammatory diseases caused by Neisseria gonorrhoeae, Chlamydia trachomatis or endometritis frequently lead to metrorrhagia/menorrhagia and reflect a frequency of less than $10 \%$ of all AUBs (23). Complaints of lower abdominal pain should suggest pelvic inflammatory disease $(6,12)$. Moreover, other possible causes of AUB (such as weight change, hirsutism and acne), chronic disorders and drug use (i.e. anticoagulants, glucocorticoids and antipsychotics) should also be investigated.

The physical examination should start with an evaluation of haemodynamics and anaemia signs. A vaginal/ cervical examination may be required to determine the source of the bleeding in certain patients (6). However, since adolescents do not tolerate this examination well, its necessity should therefore be evaluated carefully in cases of patients who are not sexually active, are at the beginning of the gynaecological maturation process, have no pelvic pain and whose history does not suggest geni-

Table 1. AUB Differential Diagnosis

\begin{tabular}{|c|c|c|c|c|c|c|}
\hline Hematological & Genital System Pathologies & Pregnancy & Endocrine & Trauma & Drugs & Other \\
\hline vWF deficiency & Fibroid, myoma & Ectopic & Hyperprolactinemia & Sexual abuse & Antipsychotics & Excessive exercise \\
\hline Thrombasthenia & Endometriosis & Implantation & $\begin{array}{l}\text { Thyroid function } \\
\text { disorders }\end{array}$ & Laceration & Anticoagulants & Eating disorders \\
\hline $\begin{array}{l}\text { Thrombocyte } \\
\text { function disorder }\end{array}$ & Polyp & Placenta accreta & Adrenal diseases & Foreign body & $\begin{array}{l}\text { Platelet } \\
\text { inhibitors }\end{array}$ & Systemic diseases \\
\hline $\begin{array}{l}\text { Coagulation } \\
\text { defects }\end{array}$ & Cervical dysplasia & $\begin{array}{l}\text { Hormonal } \\
\text { contraception }\end{array}$ & $\begin{array}{l}\text { Polycystic ovary } \\
\text { syndrome }\end{array}$ & & & Stress \\
\hline $\begin{array}{l}\text { Other factor } \\
\text { deficiencies }\end{array}$ & Infections & & Ovarian deficiency & & & $\begin{array}{l}\text { Intrauterine } \\
\text { device }\end{array}$ \\
\hline
\end{tabular}


tal-tract trauma, the presence of a foreign body, or sexual abuse (6).

Laboratory and Radiological Evaluation

Although the ideal laboratory and radiological evaluation for AUB has not been clearly identified, the initial evaluation should include the following (6):

- Whole blood count; haematocrit level

- Pregnancy test

- An examination of the structure of the uterine cavity, ovaries and endometrial thickness via pelvic ultrasonography (USG)

Severe menstrual bleeding can be the first clinical sign of coagulation disorders; it is therefore suggested that relevant tests be performed before treatment is initiated $(7,24)$.

The following tests must be completedat the beginning:

- prothrombin time/activated partial thromboplastin time

- thromboplastin time

- fibrinogen level

The following tests/measurements must be completed if there is a history of menorrhagia beginning with the first menstrual cycle:

- $\quad$ vWF antigen level

- Ristocetin cofactor activity

- $\quad$ FVIII level

A vWF level panel and platelet function studies should be performed in order to identify the subtypes in patients whose beginning tests are normal but who are strongly suspected of having a bleeding disorder $(7,25)$.

Other laboratory and radiological tests should target the diagnoses predicted as a result of the history and physical examination of the patient:

If endocrine causes are considered, the following must be checked:

- Thyroid function tests

- Prolactin levels (prolactinoma, adenoma)

- Total/free testosterone level (PCOS)

- DHEA-S04 levels (adrenal tumour)

Additionally, if infection is suspected, a vaginal swab should be performed.

\section{Treatment}

Medical and surgical treatments can be classified as hormonal and/or non-hormonal. In the acute management of patients who present with DUB, the primary aim is to ensure haemodynamic stability and, if possible, to stop the bleeding. Four main categories of treatment are administered based on bleeding severity, haemodynamic status and the patient's haemoglobin level $(6,23)$.

\section{Mild/Moderate Bleeding ( $\mathrm{Hb}>12 \mathrm{~g} / \mathrm{dL}$ )}

Hormonal treatment is not considered. Non-steroid anti-inflammatory drugs (NSAIDs) can be used. The patient should be followed up at 3-month intervals and should be instructed to keep a menstrual-cycle diary.
Moderate Bleeding ( $\mathrm{Hb} 10-12 \mathrm{~g} / \mathrm{dL}$ )

Oral contraceptives or oral progesterone can be prescribed for treatment. Monophasic oral contraceptive pills (OCPs) containing 30-35 $\mu$ g ethinyl oestradiol should be prescribed; for the first 5 days, the patient should take two pills a day. When the bleeding stops, the dose should be reduced to a single pill daily, and this regimen should be continued for 3-6 months. Progesterone-only pills can also be used for treatment and are preferred in cases where oestrogen use is contraindicated. Oral progesterone should be used at a dose of $5-10 \mathrm{mg} / \mathrm{d}$ for 12 days at the same time interval of each month (6). To replenish iron stores, iron supplements should be prescribed for at least 6 months. NSAIDs can be added to the treatment.

Severe Bleeding, Haemodynamically Stable $(\mathrm{Hb}=8-10$ $\mathrm{g} / \mathrm{dL}$ )

The use of OCPs, an approach that is similar to that for patients with moderate bleeding, is indicated if the family and the patient can comply with the treatment plan and follow-up. If there is no decrease in the severity of the bleeding following the first two doses of OCP treatment, the dose should be increased to three to 4 pills per day for 2 days; this dosage should becontinued as needed until the bleeding stops. The OCP treatment is continued at a dose of 4 pills per day for 4 days and then one pill per day for a minimum of 3-6 months. Close monitoring is important, and iron supplements should be prescribed.

Severe Bleeding ( $\mathrm{Hb} \leq 7 \mathrm{~g} / \mathrm{dL})$ or Haemodynamically Unstable

The patient should be hospitalized and monitored. Preparations should be made for blood transfusions, as they may be required. Bleeding disorders must be eliminated before starting hormonal treatment.

The first treatment of choice is to prescribe OCPs containing high doses of oestrogen (35-50 $\mu$ g ethinyl oestradiol) because OCPs promote rapid endometrial regrowth to cover denuded epithelial surfaces. The use of pills containing $50 \mu \mathrm{g}$ ethinyl oestradiol is usually considered if there is no decrease in the severity of bleeding after the second dose of the $35 \mu \mathrm{g}$ pills (26).

The treatment with high-dose oestrogen is continued at 6-hour intervals until the severity of the bleeding decreases. The dose is then decreased within 1 week as follows: one pill every 6 hours for 2 days, then every 8 hours for 2 days, then every 12 hours for 2 days and finally 1 pill daily for a minimum of 6 months. Anti-emetic therapy can be an added treatment for patients who experience highdose oestradiol-induced nausea and vomiting. The therapy is maintained with pills containing 30-35 $\mu$ g ethinyl oestradiol. However, in cases where the bleeding is controlled with $50 \mu \mathrm{g}$ high-dose ethinyl oestradiol-containing pills, these are continued for about one or two cycles at the same dose ( $50 \mu \mathrm{g}$ ethinyl oestradiol); the treatment is then continued for 3-6 months with $35 \mu \mathrm{g}$ ethinyloestradiol-containing pills (26).

Intravenous (IV) conjugated oestrogen treatment (25 
mg at intervals of 4-6 hours) may be considered for patients who cannot tolerate high-dose oral oestrogen therapy, if oral treatment is not possible due to a loss of consciousness or if the severity of bleeding does not decrease within 6-12 hours despite high-dose oral oestrogen $(17,19,26)$.

The use of conjugated oestrogen treatment for more than 24 hours is not recommended due to potential side-effects (e.g. pulmonary embolism); the treatment is therefore continued with high doses of OCPs (19).

The bleeding is usually controlled within 24 hours with OCP treatment. If the bleeding continues for more than 24-48 hours without any decrease in severity, the addition of haemostatic agents and surgery should be considered $(6,27)$.

High-dose progesterone is an alternative treatment choice in patients with severe bleeding, especially when the use of oestrogen is contraindicated (22). The progesterone reverses endometrial proliferation related to longterm estrogen exposure and induces endometrial maturation (28). Medroxyprogesterone acetate (MPA, 20-40 mg) or norethindrone acetate (NETA, 5-10 mg) are administered three times per day for 7 days (7). For patients who have been given high doses of oral MPA, the median time before the cessation of bleeding has been shown to be 3 days (28).

Another recommended treatment for acute $\mathrm{HMB}$ is depot-MPA (150 mg), administered intramuscularly and followed by MPA (20 mg) orally, every 8 hours for 9 doses (29). When the bleeding stops, the progesterone dose is decreased to every 12 hours for 2 weeks (6). Thereafter, therapy is maintained with the cyclic use of MPA (10 $\mathrm{mg} / \mathrm{d}$ ) and NETA (5 mg/d) for 12 days per month and between the same dates in every month (6).

The levonorgestrel-containing intrauterine system (LNG-IUS) is regarded as the most effective medical treatment optionforpatients with HMB, especially when longterm hormonal treatment is required (17). Its efficacy has also been demonstrated in the management of HMB in women with bleeding disorders (30). However, it is not often considered for use with adolescents due to a lack of data on its acceptability, as well as its safety, in this population. In 2007, the American College of Obstetricians and Gynecologists Committee on Adolescent Health Care concluded that available data taken from the literature support the safety of intrauterine devices for most women, including adolescent girls (7). Recent studies have confirmed this finding (22). Pelvic inflammatory disease and the possibility of perforation during insertion and/or removal of the device are the most important potential risks.

\section{Other Hormonal Treatments}

Although danazol and GnRH analogues are quite effective in the treatment of severe bleeding, they are not the first choice due to their side effects $(17,31)$. Danazol is a synthetic steroid with weak androgenic, anti-oestrogenic and anti-progestogenic activity. It causes endometrial atrophy and reduces bleeding by decreasing the number of endo- metrial oestrogen and progesterone receptors (31).

$\mathrm{GnRH}$ analogues decrease the number of pituitary $\mathrm{GnRH}$ receptors and cause suppression of gonadotropin release. They prevent menstrual cycles, and the patient becomes amenorrhoeic (21). As a last option, GnRH analogues with add-back therapy can be used, especially for patients with severe blood disorders, such as Glanzmann thrombasthenia or Bernard-Soulier syndrome, who fail to respond to other measures $(17,32)$.

\section{Non-hormonal Treatments}

Tranexamic Acid

Tranexamic acid, a lysine derivative, is bound to lysine in its fibrinogen structure. Tranexamic acid prevents the destruction of fibrin and decreases bleeding by 30\%-55\% (33). However, it has no effect on the duration of bleeding or on the regulation of the menstrual cycle (17). The recommended dose and duration are 3-4 doses of 1-1.5 $\mathrm{g} / \mathrm{d}$ orally or $10 \mathrm{mg} / \mathrm{kg}$ intravenously (maximum $600 \mathrm{mg}$ / dose) per day for 5 days (25).

\section{Non-steroidal Anti-inflammatory Drugs}

NSAIDs decrease bleeding by preventing prostacyclin formation. Their use is especially recommended for the treatment of ovulatory DUB (1). It has been reported that the circulating total prostaglandin levels of females with menorrhagia are high and that bleeding can be decreased only with NSAIDs in these patients $(15,34)$. However, until a work-up has been completed, adolescents with HMB and a possible history of bleeding disorders should be instructed to avoid NSAIDs due to decreased platelet aggregation by inhibiting thromboxane A2 synthesis (17).

It has been reported that NSAIDs decrease bleeding 25\%-35\% compared to placebos but that they are less effective when compared with other treatments (e.g. tranexamic acid, danazol and IUDs) (34). The recommended usage for mefenamic acid is $500 \mathrm{mg} /$ dose at intervals of 3-5 hours on the first day and a 250 - or $500-\mathrm{mg}$ dose three to 4 times per day thereafter. The recommended dose for naproxen is $500-550 \mathrm{mg}$ at intervals of 3-5 hours on the first day and 250-275 mg 4 times per day, while ibuprofen is recommended at $600-1200 \mathrm{mg} / \mathrm{d}$ following the start of menstrual bleeding (34). No difference in the effectiveness of naproxen versus ibuprofen has been demonstrated (34).

\section{Desmopressin}

Desmopressin is a synthetic analogue of arginine-vasopressin. It is used to control and to prevent bleeding episodes in patients with a coagulation disorder (17). Desmopressin increases the vWF and FVIII levels, as well as platelet adhesion, and its effects last for about 6 hours (17).

The literature contains various recommendations regarding dose and duration of desmopressin use. However, bleeding control is generally ensured in $80 \%-92 \%$ of patients who take desmopressin nasally, $300 \mu \mathrm{g} / \mathrm{d}$, divided into 2 or 3 doses in the first 2-3 days of the cycle (35).

Desmopressin combined with tranexamic acid is recommended as a good treatment option for adolescents 
who do not want hormone treatment (17).

Possible side effects due to the vasomotor and antidiuretic effects are headache, mild tachycardia, hyponatremia and, rarely, water intoxication (17).

\section{Surgical Treatment}

More than $90 \%$ of the severe bleeding that occurs in adolescents is controlled with medical treatment (8). However, surgery is required in the event of life-threatening bleeding, when medical treatment is unsuccessful and in situations where a histopathology evaluation is needed. Dilatation and curettage, uterine artery embolization, endometrial ablation and hysterectomy are surgical treatment options (25). The decision to proceed with surgical treatment should be made after taking into account the fertility desire of the patient. Mechanical methods, such as the use of Foley catheter balloons, have also been shown to be useful for bleeding control (25).

In conclusion, DUB is an important clinical condition commonly encountered in the adolescent age group. It decreases the quality of life and is worrisome for both the patient and family. During the acute period of bleeding management, the treatment should be determined while considering the cause and severity of the bleeding. While evaluations to determine the cause should be completed, treatments that will rapidly restore haemodynamic stability should be administered via an algorithm for patients with severe bleeding. With respect to long-term treatment and/or follow-up, hormonal treatments can be safely used with adolescents; moreover, they have positive effects on school performance and on the social activities of this group by decreasing the number and severity of bleeding episodes without damaging the hormonal axis during the maturation process.

\section{Ethical Issues}

Not applicable.

\section{Conflict of Interests}

The authors declare no conflicts of interests.

\section{References}

1. Carswell J, Stafford D. Normal physical growth and development. In: Neinstein LS, Gordon CM, Katzman DK, Rosen DS, Woods ER, eds. Adolescent Health Care: A Practical Guide. 5th ed. Philadelphia: Lippincott Williams \& Wilkins; 2008:3-26.

2. Rosenfield RL, Cooke DW, Radovick S. Puberty and its disorders in the female. In: Sperling MA, ed. Pediatric Endocrinology. USA: Elsevier Health Sciences; 2014:569663.

3. Gray SH, Emans SJ. Abnormal vaginal bleeding in adolescents. Pediatr Rev. 2007;28(5):175-182. doi:10.1542/ pir.28-5-175.

4. World Health Organization Task Force on Adolescent Reproductive Health. World Health Organization multicentre study on menstrual and ovulatory patterns in adolescent girls. II. Longitudinal study of menstrual patterns in the early postmenarcheal period, duration of bleeding episodes and menstrual cycles. J Adolesc Health Care. 1986;7:236-44. doi:10.1016/S0197-0070(86)80015-8.

5. Mitan LA, Slap GB. Dysfunctional uterine bleeding. In: Neinstein LS, ed. Handbook of Adolescent Health Care. Philadelphia: Lippincott Williams \&Wilkins; 2009:467-9.

6. Deligeoroglou E, Karountzos V, Creatsas G. Abnormal uterine bleeding and dysfunctional uterine bleeding in pediatric and adolescent gynecology. Gynecol Endocrinol. 2013;29(1):74-8. doi:10.3109/09513590.2012.705384.

7. American College of Obstetricians and Gynecologists. ACOG committee opinion no. 557: Management of acute abnormal uterine bleeding in non-pregnant reproductiveaged women. Obstet Gynecol. 2013 ;121(4):891-6. doi:10. 1097/01.AOG. 0000428646. 67925.9a.

8. Frishman GN. Evaluation and treatment of menorrhagia in an adolescent population. J Minim Invasive Gynecol. 2008;15(6):682-8. doi:10.1016/j.jmig.2008.08.014.

9. Cakir M, Mungan I, Karakas T, Girisken I, Okten A. Menstrual pattern and common menstrual disorders among university students in Turkey. Pediatr Int. 2007;49(6):93842. doi:10.1111/j.1442-200X.2007.02489.x

10. Lee LK, Chen P, Lee KK, Kaur J. Menstruation among adolescent girls in Malaysia: a cross-sectional school survey. Singapore Med J. 2006;47(10):869-74.

11. Fraser IS, Sungurtekin U. Defining menstrual disturbances. In: Maclean A, O’Brien PMS, eds. Study Group on Menstrual Disorders. London: Royal College of Obstetricians and Gynecologist; 2000:141-52.

12. Creatsas M, Creatsas GK. Dysfunctional uterine bleeding during adolescence. In: Frontiers in Gynecological Endocrinology ISGE Series (Volume 1). USA: Springer; 2014:9-14.

13. Kalogeropoulos A. Menstrual disorders and abnormal genital tract bleeding. In: Kalogeropoulos A, ed. Gynecology. 2nd ed. Thessaloniki: University Studio Press; 2004:419-50.

14. Pitkin J. Dysfunctional uterine bleeding. BMJ. 2007;334(7603):1110-1.

15. Baird DT, Cameron ST, Critchley HO, et al. Prostaglandins and menstruation. Eur J Obstet Gynecol Reprod Biol. 1996;70(1):15-17. doi:10.1016/S0301-2115(96)02568-7.

16. Smith SK, Abel MH, Kelly RW, Baird DT. Prostaglandin synthesis in the endometrium of women with ovular dysfunctional uterine bleeding. Br J Obstet Gynaecol. 1981;88(4):434-42. doi:10.1111/j.1471-0528.1981. tb01009.x

17. Wilkinson JP, Kadir RA. Management of abnormal uterine bleeding in adolescents. J Pediatr Adolesc Gynecol. 2010;23(6 Suppl):S22-S30. doi:10.1016/j.jpag.2010.08.007.

18. Vihko R, Apter D. Endocrine characteristics of adolescent menstrual cycles: impact of early menarche. J Steroid Biochem. 1984;20(1):231-6. doi:10.1016/00224731(84)90209-7.

19. Brown DL. Congenital bleeding disorders. Curr Probl Pediatr Adolesc Health Care. 2005;35(2):38-62. doi:10.1016/j.cppeds.2004.12.001.

20. Emans SJ. Dysfunctional uterine bleeding. In: Emans SJ, Laufer MR, Goldstein D, eds. Pediatric \& Adolescent Gynecology. 5th ed. Philadelphia: Lippincott Williams \&Wilkins; 2005:270-86.

21. Jayasinghe Y, Moore P, Donath S, Campbell J, Monagle P, Grover S. Bleeding disorders in teenagers presenting with menorrhagia. Aust N Z J Obstet Gynecol. 2005;45(5):439- 
43. doi:10.1111/j.1479-828X.2005.00470.x.

22. Sokkary N, Dietrich JE. Management of heavy menstrual bleeding in adolescents. Curr Opin Obstet Gynecol. 2012;24(5):275-80. doi:10.1097/GCO.0b013e3283562bcb.

23. Deligeoroglou E, Tsimaris P. Menstrual disturbances in puberty. Best Pract Res Clin Obstet Gynaecol. 2010;24(2):157-71. doi:10.1016/j.bpobgyn.2009.11.001.

24. Kulp J, Mwangi C, Loveless M. Screening for coagulation disorders in adolescents with abnormal uterine bleeding. J Pediatr Adolesc Gynecol. 2008;21(1):27-30. doi:10.1016/j. jpag.2007.04.002.

25. James A, Kouides P, Abdul-Kadir R, Dietrich JE, Edlund $M$, Federici $A B$, et al. Evaluation and management of acute menorrhagia in womenwith and without underlying bleeding disorders: consensus from international expert panel. Eur J Obstet Gynecol Reprod Biol. 2011;158(2):12434. doi:10.1016/j.ejogrb.2011.04.025.

26. Slap GB. Menstrual disorders in adolescence. Best Pract Res Clin Obstet Gynaecol. 2003;17(1):75-92. doi:10.1053/ ybeog.2002.0342.

27. Mannucci PM. Treatment of vonWillebrand disease. N Engl J Med. 2004;351(7):683-94. doi:10.1046/j.13652516.1998.440661.x

28. Munro MG, Mainor N, Basu R, Brisinger M, Barreda L. Oral medroxyprogesterone acetate and combination oral contraceptives for acute uterine bleeding: a randomized controlled trial. Obstet Gynecol. 2006;108(4):924-9. doi:10.1097/01. AOG.0000238343.62063.22.
29. Ammerman SR, Nelson AL. A new progestogenonly medical therapy for outpatient management of acute, abnormal uterine bleeding: a pilot study. Am J Obstet Gynecol. 2013;208(6):499e1-5. doi:10.1016/j. ajog.2013.02.013.

30. Kingman C, Kadir R, Lee C, Economides D. The uses of levonorgestrel-releasing intrauterine system for treatment of menorrhagia in women with inherited bleeding disorders. BJOG. 2004;111(12):1425-8. doi:10.1111/j.14710528.2004.00305.x

31. Beaumont H, Augood C, Duckitt K, Lethaby A. Danazol for heavy menstrual bleeding. Cochrane Database Syst Rev 2007;(3):CD001017. doi:10.1002/14651858.CD001017. pub2

32. Speroff L, Glass RH, Kase NG. Dysfunctional uterine bleeding. In: Speroff L, Glass RH, Kase NG, eds. Clinical Gynecologic Endocrinology and Infertility. 5th ed. Baltimore: Williams \& Wilkins; 1994:575-93.

33. Lethaby A, Farquhar C, Cooke I. Antifibrinolytics for heavy menstrual bleeding. Cochrane Database Syst Rev 2000;(4):CD000249. doi:10.1002/14651858.CD000249.

34. Lethaby A, Duckitt K, Farquhar C. Non-steroidal antiinflammatory drugs for heavy menstrual bleeding. Cochrane Database Syst Rev 2013 Jan 31;(1):CD000400. doi:10.1002/14651858.CD000400.pub3.

35. Kujovich JL. vonWillebrand's disease and menorrhagia: prevalence, diagnosis, and management Am J Hematol 2005 Jul;79(3):220-8. doi:10.1002/ajh.20372.

Copyright (c) 2017 The Author (s); This is an open-access article distributed under the terms of the Creative Commons Attribution License (http://creativecommons.org/licenses/by/4.0), which permits unrestricted use, distribution, and reproduction in any medium, provided the original work is properly cited. 